\title{
Jurnal Silva Samalas

\section{IDENTIFIKASI TINGKAT KERUSAKAN PADA TANAMAN KOPI YANG DI SEBABKAN OLEH HAMA DI DESA KARANG SIDEMEN KECAMATAN BATUKLIANG UTARA KABUPATEN LOMBOK TENGAH}

\author{
Robi Dwi Permana*, LL. Suhirsan Masrilurrahman \\ aprogram Studi Kehutanan Universitas Pendidikan Mandalika, Jl. Pemuda No 59A Dasan Agung, Mataram \\ * Corresponding author: robidwipermana02@gmail.com
}

\begin{abstract}
Coffee is a plantation commodity that is abundant in Indonesia. This plant thrives in the highlands, which is above 700 meters above sea level (above sea level). The potentials, there are main problems in smallholder coffee plantations, namely low productivity and quality that does not meet export standards. Low productivity of coffee is partly caused by the attack of Plant Pest Organisms (OPT). OPT attacks can cause economic losses both in quality and quantity. Therefore, what underlies the author to conduct research is to identify the level of damage to coffee plants caused by pests in Karang Sidemen Village which is one of the coffee centers on the island of Lombok, especially Central Lombok Regency. Descriptive research method is collecting primary and secondary data. Primary data analysis was obtained from interviews with the "Harapan Kita" Farmers Group with 3 Respondents, Plant Sample Observations, documentation. Meanwhile, secondary data analysis was obtained from literature studies, such as a general description of the area obtained from the archives of the local agency or concerned, namely Karang Sidemen Village. Based on the results of data collection, it can be identified the level of damage to coffee plants caused by pests, namely stem borers, fruit borers, mealybugs. With the level of damage based on 3 categories of damage, namely mild 62\%, moderate 32\%, severe 6\%. The conclusion of the identification of the level of damage to coffee plants is in the form of damage to the stems, leaves and fruit
\end{abstract}

Keywords: The level of damage, Coffee, Pests

\begin{abstract}
Abstrak
Kopi merupakan tanaman komoditas perkebunan yang melimpah luas di Indonesia.Tanaman ini hidup subur didaerah dataran tinggi, yaitu diatas 700 meter dpl (diatas permukaan laut). Dengan potensi tersebut terdapat permasalahan utama pada perkebunan kopi rakyat, yaitu rendahnya produktivitas dan mutu yang kurang memenuhi standar ekspor. Rendahnya produktivitas kopi antara lain disebabkan oleh serangan Organisme Pengganggu Tanaman (OPT). Serangan OPT dapat menimbulkan kerugian secara ekonomis baik kualitas maupun kuantitas. Oleh sebab itu yang mendasari penulis untuk melakukan penelitian identifikasi tingkat kerusakan tanaman kopi yang disebabkan oleh hama di Desa Karang Sidemen yang merupakan salah satu sentra kopi di Pulau Lombok, khususnya Kabupaten Lombok Tengah. Metode penelitian deskriptif yaitu mengumpulkan data primer dan sekunder. Analisis data primer diperoleh dari wawancara Kelompok Tani "Harapan Kita" dengan 3 Responden, Pengamatan Sampel Tanaman, dokumentasi. Sedangkan analisis data sekuder diperoleh dari studi literatur, seperti gambaran umum wilayah yang diperoleh dari arsip instansi setempat atau yang bersangkutan yaitu desa karang sidemen. Berdasarkan hasil pengumpulan data dapat identifikasi tingkat kerusakan tanaman kopi disebabkan oleh hama yaitu penggerek batang, penggerek buah, kutu putih. Dengan tingkat kerusakan berdasarkan 3 kategori kerusakan yakni ringan $62 \%$, sedang 32\%, berat 6 $\%$. Kesimpulan identifikasi tingkat kerusakan tanaman kopi yaitu berupa kerusakan di batang, daun dan buah.
\end{abstract}

Kata Kunci: Tingkat kerusakan, Kopi, Hama

How to Cite: Permana, R. B. dan Masrilurrahman, L. L. S. (2021) 'Identifikasi Tingkat Kerusakan pada Tanaman Kopi yang di Sebabkan oleh Hama di Desa Karang Sidemen Kecamatan Batukliang Utara Kabupaten Lombok Tengah', Jurnal Silva Samalas: Journal of Forestry and Plant Science, 4 (1), pp. 10-14. 
PENDAHULUAN

Kopi merupakan salah satu jenis tanaman perkebunan yang sudah lama dibudidayakan dan memiliki nilai ekonomis yang lumayan tinggi. Konsumsi kopi dunia mencapai $70 \%$ berasal dari spesies kopi arabika dan 26\% berasal dari spesies kopi robusta. Kopi berasal dari Afrika, yaitu daerah pegunungan di Etopia. Namun, kopi sendiri baru dikenal oleh masyarakat dunia setelah tanaman tersebut dikembangkan diluar daerah asalnya, yaitu Yaman dibagian selatan Arab, melalui para saudagar Arab (Rahardjo, 2012).

Di Indonesia kopi mulai di kenal pada tahun 1696, yang dibawa oleh VOC. Tanaman kopi di Indonesia mulai diproduksi dipulau Jawa, dan hanya bersifat coba-coba, tetapi karena hasilnya memuaskan dan dipandang oleh VOC cukup menguntungkan sebagai komoditi perdagangan maka VOC menyebarkannya ke berbagai daerah agar para penduduk menanamnya (Najiyati dan Danarti, 2004).

Kopi merupakan tanaman komoditas perkebunan yang melimpah luas di Indonesia.Tanaman ini hidup subur didaerah tinggi, yaitu diatas 700 meter dpl (diatas permukaan laut). Berdasarkan data Statistik Perkebunan Indonesia (SPI), Produksi kopi di Indonesia yakni 637.539 ton/tahun dengan luas lahan 1.227.787 Ha, sedangkan di Nusa Tenggara Barat produksi kopi dengan potensi limbah kulit kopi 4.615 ton/tahun dengan luas lahan $11.902 \mathrm{Ha}$ (Anonim, 2017).

Desa Karang sidemen merupakan salah satu desa di kecamatan batukliang utara yang masih banyak terdapat lahan perkebunan. Salah satu jenis tanaman perkebunan yang banyak dikembangkan yakni kopi robusta (Coffea canephora). (Anonim, 2018)

Dengan potensi tersebut terdapat permasalahan utama pada perkebunan kopi rakyat, yaitu rendahnya produktivitas dan mutu yang kurang memenuhi standar ekspor. Rendahnya produktivitas kopi antara lain disebabkan oleh serangan Organisme Pengganggu Tanaman (OPT). Serangan OPT dapat menimbulkan kerugian secara ekonomis baik kualitas maupun kuantitas. Serangan OPT tidak hanya pada tanaman dewasa di lapang tetapi juga di pembibitan, kebun entres, dan penyimpanan. OPT pada tanaman kopi di antaranya adalah kelompok hama dan penyakit. Hama pada tanaman kopi adalah penggerek buah kopi, penggerek batang merah, penggerek cabang dan ranting, kutu hijau, dan Sanurus indecora. Penyakit tanaman kopi dibagi atas penyakit yang disebabkan oleh jamur, yaitu karat daun, bercak daun, jamur upas, jamur akar, kanker belah, penyakit rebah batang, dan penyakit yang disebabkan oleh nematoda (Harni Rita, $d k k ., 2015$ ).

Pengendalian terhadap hama dan penyakit tanaman kopi dilakukan bertujuan menekan perkembangan populasi hama dan patogen agar tidak merugikan secara ekonomis dan meningkatkan ketahanan tanaman. Komponen pengendalian antara lain penggunaan varietas tahan, kultur teknis, biologi/hayati, pestisida sintetik, dan nabati. Upaya pengendalian dapat dilakukan secara tunggal maupun terpadu antara beberapa komponen yang kompatibel dan sesuai dengan lingkungan.

Pada dasarnya di industri kopi Indonesia masih ditemukan permasalahan yaitu produktivitas dan kualitas hasil komoditi perkebunan rakyat masih cukup rendah. Salah satu faktor penyebabnya antara lain disebabkan oleh petani yang belum memperhatikan penerapan Pengendalian Hama Terpadu (PHT) pada area kebunnya, sehingga kerugian hasil akibat serangan Organisme Pengganggu Tumbuhan (OPT) terutama hama dan penyakit tanaman cukup besar (Aditya Wahyu, 2015).

Oleh sebab itu yang mendasari penulis untuk melakukan penelitian di Desa Karang Sidemen yang merupakan salah satu sentra kopi di Pulau Lombok Khususnya Kabupaten Lombok Tengah. Kedepannya diharapkan dengan adanya penelitian ini, akan menjadi gambaran bagi petani dalam melakukan pemeliharaan tanaman kopi khususnya Organisme Pengganggu Tumbuhan (OPT) untuk pengendalian hama tanaman

\section{METODE PELAKSANAAN}

Penelitian ini merupakan penelitian deskriptif kualitatif. Penelitian deskriptif yaitu mengumpulkan data berdasarkan faktor-faktor yang menjadi pendukung terhadap objek peelitian, kemudian menganalisa faktor-faktor tersebut untuk mencari perannya (Arikuto, 2010).

\section{a. Cara Kerja}


Pengisian kuisioner dan wawancara dengan 3 responden pada kelompok tani "HARAPAN KITA" di desa Karangsidemen kec. Batukliang Utara. Pengamatan Sampel Tanaman: Pengambilan sampel tanaman berdasarkan informasi dari informan yang menjadi narasumber, kemudian dilakukan pencatatan meliputi jenis hama, jenis kerusakan, kategori kerusakan dan tingkat kerusakan yang disebabkan oleh hama dan lokasi pengambilan sampel tanaman kopi yang terserang hama.

Dokumentasi: Sistem pendokumentasian wawancara menggunakan foto digital. Dokumentasi tanaman kopi yang terserang hama menggunakan foto digital, dokumentasi juga dilakukan mencakup kondisi wilayah dan tanaman kopi di desa karang sidemen kecamatan Batukliang Utara. Dokumentasi ini juga dilakukan dengan cara mengambil gambar jenis hama apa saja yang menyerang tanaman kopi.

Pengumpulan data sekunder dengan cara melakukan studi literatur, seperti gambaran umum wilayah yang diperoleh dari arsip instansi setempat atau yang bersangkutan yaitu Desa Karang Sidemen yang terdapat di kecamatan Batukliang Utara.

\section{b. Analisis Data}

Data yang dihasilkan dari proses wawancara digunakan sebagai gambaran sebelum observasi. Setelah didapatkan data responden tersebut dilakukan obeservasi kualitatif yakni dengan menentukan 3 responden dan sampel tanaman yang akan diamati, melakukan pencatatan jenis hama, jenis kerusakan dan katogeri kerusakan. Setelah terkumpul data hasil observasi, kemudian diberikan persentase tingkat serangan hama berdasarkan selisih jumlah sampel dengan jumlah tidak ada serangan.

Sebelum melakukan observasi dilakukan identifikasi jenis hama secara menyeluruh, yang didapatkan informasi dari literature dan informan. Identifikasi hama berupa penggolongan jenis hama, bagian yang diserang, akibat kerusakan

\section{HASIL DAN PEMBAHASAN}

\section{a. Identifikasi Hama Tanaman Kopi di Desa Karang Sidemen}

Terdapat 2 hama utama pada tanaman kopi di Desa karang Sidemen. Yang pertama adalah hama penggerek batang (Zeuzeura coffeae). Yang kedua adalah hama penggerek buah (Hypothenemus hampei). Kedua hama tersebut memiliki perkembangan biologis dan gejala serangan yang bervariasi.

Telur hama Zeuzera coffeae berwarna kuning kemerahan /kuning ungu dan akan berubah menjadi kuning kehitaman, menjelang menetas. Telur diletakkan dicelah kulit kayu. Ulat berwarna merah cerah sampai ungu, sawo matang, panjangnya $3-5 \mathrm{~cm}$. Kepompong dibuat dalam lianggerekan. Sayap depan ngengat berbintik hitam dengan dasar putih tembus pandang. Seekor betina dapat meletakkan telur 340-970 butir.

Ulat ini merusak bagian batang/cabang dengan cara menggerek empulur (xylem) batang/cabang, selanjutnya gerekan membelok ke arah atas. Menyerang tanaman muda. Pada permukaan lubang yang baru digerek sering terdapat campuran kotoran dengan serpihan jaringan. Akibat gerekan ulat, bagian tanaman di atas lubang gerekan akan merana, layu, kering dan mati.

Cara pengendalian dengan menutup lubang gerekan, dan ulat yang ditemukan dimusnahkan. Cara lain adalah memotong batang/cabang terserang $10 \mathrm{~cm}$ di bawah lubang gerekan, kemudian ulatnya dimusnahkan/dibakar.

Kumbang betina hama pengerek buah menggerek ke dalam biji kopi dan bertelur sekitar 30-50 butir. Telur menetas menjadi larva yang menggerek biji kopi. Larva menjadi kepompong di dalam biji. Dewasa (kumbang) keluar dari kepompong. Jantan dan betina kawin di dalam buah kopi, kemudian sebagian betina terbang ke buah lain untuk masuk, lalu bertelur lagi. Jantan tidak bisa terbang sehingga tetap di dalam buah tempat lahirnya sepanjang hidup.

PBKo sangat merugikan, karena mampu merusak biji kopi dan sering mencapai populasi yang tinggi. Pada umumnya, hanya kumbang betina yang sudah kawin yang akan menggerek buah kopi; biasanya masuk buah dengan buat lubang kecil dari ujungnya. Kumbang betina menyerang buah kopi yang sedang terbentuk, dari 8 minggu setelah berbunga sampai waktu panen. Buah yang sudah tua paling disukai. 
Cara-cara yang disarankan untuk mengendalikan penggerek buah kopi yaitu dengan pengendalian secara hayati memakai jamur Beauveria bassiana. Petik merah (buah yang masak pertama) buah yang terserang PBKo, dikumpulkan dan diperlakukan dengan $B b$, kemudian ditutup dengan plastik jernih. Biarkan satu malam. Dewasa akan keluar dari buah dan terinfeksi oleh $B b$; dewasa ini kelihatan di bawah plastik. Dewasa tersebut dilepas sehingga dapat menularkan $B b$ kepada pasangannya di kebun.

Pengambilan titik sampel berpusat di dusun sintung timur, karena di lokasi tersebutt merupakan pusat tanaman kopi di Desa Karang Sidemen. Daerah Dusun Sintung Timur memiliki topografi yang sesuai dengan tanaman kopi, dibandingkan dengan dusun lain yang lebih rendah topografinya. Hal tersebut yang melatarbelakangi di daerah tersebut dibuat kelompok tani kopi dan kakao. Pengambilan titik sampel dilakukan di lahan pak umar (ketua kelompok tani) dengan luas lahan 1,8 $\mathrm{Ha}$, jarak tanam kopi 2,5 m x $3 \mathrm{~m}$ dengan sistem mixed cropping dengan tanaman kakao. Jadi, populasi tanaman yang didapatkan dengan luas areal tersebut yakni \pm 2.400 tanaman kopi.

\section{b. Persentase Tingkat Kerusakan oleh Hama di Desa Karang Sidemen}

Tabel 1. Persentase Kerusakan Hama pada Tanaman Kopi di Desa Karang Sidemen

\begin{tabular}{llll}
\hline No & Kategori Kerusakan & $\begin{array}{l}\text { Persentase Kerusakan }(\%) / 50 \\
\text { (Pohon) }\end{array}$ & Total \\
\hline 1 & Ringan & 62 & 31 \\
\hline 2 & Sedang & 32 & 16 \\
\hline 3 & Berat & 6 & 3 \\
\hline & Total & 100 & 50 \\
\hline
\end{tabular}

Kerusakan dibedakan menjadi tiga kategori yaitu ringan, sedang dan berat. Kategori ringan jika tanaman tetap dapat berproduksi secara optimal, tunas baru tetap dapat tumbuh, meskipun terdapat serangan hama pada beberapa bagian organ. Kategori sedang jika tanaman tetap dapat berproduksi secara optimal, perkembangan tunas dan bagian organ mulai terhambat karena serangan hama. Kategori berat jika tanaman mulai tidak mampu berproduksi, tanaman berbuah namun mengalami pembusukkan, beberapa organ vegetatif mengering dan membusuk. Hasil persentase kerusakan oleh hama yang menyerang tanaman kopi di desa Karangsidemen dominasi adalah $62 \%$ dari jumlah sampel tanaman kopi sebanyak 50 dengan kategori ringan yaitu 31 pohon. Walaupun begitu, pengendalian hama tetap harus intensif dilakukan untuk tetap dapat menekan perkembangan hama. Salah satu kegiatan pemeliharaan yang dapat dilakukan yakni pemangkasan pemeliharaan dengan memotong bagian-bagian batang dengan tujuan untuk meningkatkan masuknya sinar matahari, sehingga dapat menekan perkembangan hama

\section{KESIMPULAN}

Berdasarkan hasil penelitian dapat ditarik kesimpulan sebagai berikut : pada tanaman kopi di Desa Karang Sidemen adalah 62\% kategori ringan, 32\% kategori sedang dan $6 \%$ kategori berat. Jenis kerusakan yang ditimbulkan oleh hama pada kopi yaitu berupa kerusakan di batang, daun dan buah

\section{SARAN}

Saran yang dapat disampaikan adalah perlu adanya penelitian lanjutan untuk mengetahui intensitas serangan hama di Desa Karang Sidemen.

\section{DAFTAR PUSTAKA}

Aditya, Wahyu, N (2015). Perancangan Sistem Pakar Pendeteksi Penyakit Pada Tanaman Kopi Dengan Layanan Berbasis Lokasi. Universitas Binus Jakarta.

Anonim, 2017. Anonim, 2017.Statistik Perkebunan Indonesia. 
Anonim, 2018. Profil Desa Karangsidemen Kec. Batukliang Utara. Lombok Tengah.

Arikunto, S. 2010. Prosedur Penelitian Suatu Pendekatan Praktik. Jakarta: Rineka Cipta.

Harni, R..,Taufiq, E., Martono, B (2015). Ketahanan Pohon Induk Kopi Liberika Terhadap Penyakit Karat Daun (Hemileia Vastatrix B. Et Br.) Di Kepulauan Meranti. Jurnal tanaman Industri dan penyegar 2 (1), 35-42

Najiyati dan Danarti. 2004. Kopi Budidaya dan Penanganan Lepas Panen, Edisi Revisi. Jakarta. Penebar Swadaya

Rahardjo, Pudji. 2012. Panduan Budidaya dan Pengolahan Kopi Arabika dan Robusta. Penebar Swadaya. Jakarta. 